\title{
IGREJA E NORMALIZAÇÃO DE PROFESSORES EM SÃO JOÃO DEL-REI (MINAS GERAIS)
}

\author{
Maria Aparecida Arruda \\ Universidade Federal de São João del-Rei, Brasil.
}

$\cos 8$

\section{Resumo}

Este trabalho foi construído a partir da aproximação entre a história da educação e o tema da formação docente pelo viés do ensino confessional católico. Para tal, foi empreendido um estudo acerca do Curso Normal ofertado pelo Colégio Nossa Senhora das Dores, fundado em 1898 na cidade de São João del-Rei (MG), em que se buscava formar professoras para atuar em outros níveis de ensino. Tendo em vista sua equiparação, em 1905, às escolas normais oficiais do Estado de Minas Gerais, busquei investigar o modo como foi instituído esse novo estatuto jurídico em meio aos acontecimentos que o precederam.

Palavras-chave: formação docente, educação feminina, escola normal.

\section{CHURCH AND STANDARDS FOR TEACHERS IN SÃO JOÃO DEL-REI (MINAS GERAIS)}

\section{Abstract}

This work intends to relate of History Education and Teacher Training from the perspective of catholic teaching. The study was undertaken about the Teaching Course, offered by the High Scholl called Colégio Nossa Senhora das Dores, founded in 1898 in São João del-Rei, Minas Gerais. The propose of the course was to train teachers to work in different levels of learning. In 1905 , the course obtained the equivalence to the official teacher's college in Minas Gerais. The study tried to investigate how the new legal status was established among the events that precede this jurisdiction.

Key-words: teacher education, female education, teacher training high school.

\section{IGLESIA Y LAS NORMAS PARA LOS MAESTROS EN LA SÃO JOÃO DEL-REI (MINAS GERAIS)}

\section{Resumen}

Este trabajo se basa en la aproximación de la Historia de la Educación y el tema de la formación del profesorado por la perspectiva de la enseñanza confesional católica. Para ello, se realizó un estudio en el curso normal ofrecido por el Colegio Nuestra Señora de los Dolores, fundada en 1898 en São João del-Rei, Minas Gerais, que trataba de formar a los profesores para trabajar en 
otros niveles de educación. Teniendo en cuenta su asimilación en el año 1905, las escuelas oficiales normales del Estado de Minas Gerais, trató de investigar la forma en que se estableció este nuevo estatus jurídico entre los acontecimientos que la precedieron.

Palabras-clave: formación de docentes, la educación femenina, la escuela normal.

\section{ÉGLISE ET LA NORMALISATION DES ENSEIGNANTS À SÃO JOÃO DEL REI (MINAS GERAIS)}

\section{Résume}

Ce travail a été construit par le rapprochement entre l'histoire de l'éducation et le thème de la formation des maitres par le biais de l'éducation confessionnelle catholique. À cette fin, on a entrepris une étude sur les cours Normal offert par le Collège Nossa Senhora das Dores, fondée en 1898 dans la ville de Sao João del Rei, Minas Gerais, orientée vers la formation des enseignants qui doivent agir sur les autres niveaux d'enseignement. Compte tenu de leur euiparation, en 1905, à des écoles normales officielle de l'état de Minas Gerais, on a cherché le façon dont ce nouveau statut juridique il a été mis au milieu des événements qui l'ont précédé. Mots-clé: formation d'enseignant, l'éducation des femmes, école normale.

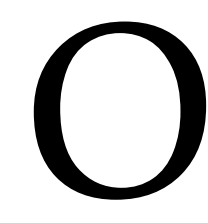

presente estudo focaliza os movimentos que configuraram o processo de formação docente em São João del-Rei, buscando aprofundar a compreensão em torno da história da formação de professores primários em Minas Gerais.

Por meio da pesquisa realizada busquei compreender aspectos da história da educação na região do Campo das Vertentes, onde está localizada a cidade de São João del-Rei. Compreender o mecanismo da formação de professores, seu aparecimento, funcionamento, transformações e efeitos, constituiu peça fundamental do investimento.

Neste caso, me situo entre os que auxiliam na tarefa de pensar a história educacional de São João del-Rei, entre o final do século 19 e início do 20, procurando dar a ver as tradições forjadas ou inventadas no campo da docência e de sua formação prévia. Busquei desenvolver o estudo pelo viés do ensino privado confessional, da presença religiosa no espaço de formação, tendo como alvo o público feminino. $A$ análise tem como referencial empírico documentos relacionados ao Colégio Normal Nossa Senhora das Dores (CNSD), instalado na cidade no ano de 1898.

\section{Os acasos do começo e a pedagogia vicentina}

O CNSD foi fundado pela Filhas da Caridade da Sociedade São Vicente de Paulo, que se instalaram no Brasil na década de 1840. Foi em Mariana, Província de Minas 
Gerais, que as freiras vicentinas iniciaram as ações missionárias e educacionais no Brasil sob orientação do bispo D. Antônio Ferreira Viçoso ${ }^{1}$.

De procedência francesa, as Filhas da Caridade se instalaram no Brasil na década de 1840, em meio ao movimento de expansão das atividades assistenciais e sociais da Igreja Católica do século 19, tendo como propósito desenvolver ações pastorais e educacionais. No que se refere a São João del-Rei, pode-se aferir que a criação do CNSD esteve intimamente relacionada à vinda das freiras vicentinas para a cidade, em 1890. Vieram para atender ao chamado dos administradores da Santa Casa de Misericórdia para exercer funções assistenciais.

Suas ações, no entanto, foram expandidas com a criação e organização de um externato, a construção de um prédio para o recolhimento das expostas e um colégio que arrecadaria fundos para a manutenção das órfãs. Se considerarmos o conjunto dessas ações em sentido ampliado, observamos entrelaçamentos que reúnem educação e caridade, sendo, às vezes, mais caritativos do que educacionais. No caso em questão, esse complexo institucional encontra-se articulado, entrelaçado, visceralmente cruzado.

As ações, por sua vez, eram vinculadas a um rigoroso sistema de normatizações em conexão com a Casa Mãe de Paris $^{2}$ e consistiam no atendimento aos pobres em suas casas, em hospitais e escolas para meninos e meninas, orfanatos, asilos, casas para loucos, casas de saúde, prisioneiros e outros.

O projeto educacional das Filhas da Caridade esteve inserido, em sentido amplo, no que ficou conhecido como processo de romanização do catolicismo no Brasil, movimento que se mostrava resistente às liberdades modernas. Dirigido pela alta hierarquia eclesiástica visava, em um primeiro momento, a desvincular a Igreja da Coroa lusobrasileira e colocá-la diretamente sob as ordens da Santa Sé. Duas foram as principais preocupações dos reformadores: o clero e o povo cristão.

Em Minas Gerais, o bispo de Mariana, o padre lazarista D. Antônio Ferreira Viçoso, se destacou entre os prelados que lideraram esse projeto. Ele foi responsável pela vinda das vicentinas para o Estado e pela instalação dos colégios femininos, como o Providência, em 1849, em Mariana, o Nossa Senhora das Dores, em Diamantina, em 1867 (Muniz, 2003) e, na sequência desse movimento, já não mais no período do bispado

\footnotetext{
${ }^{1}$ D. Antônio Ferreira Viçoso foi bispo de Mariana no período de 1844-1875.

${ }^{2}$ Segundo Leonardi (2009), um modelo de organização das congregações religiosas que se tornou dominante na França durante o século 19 se pautou na conexão das congregações com a superiora geral. Segundo a autora, "essas instituições tinham a possibilidade de se desenvolver em diversos lugares, mas sempre ligadas à superiora geral e a uma sede, chamada Casa Geral ou Casa Mãe, de onde emanavam todas as ordens e decisões sobre os rumos da Congregação: recrutamento, trabalhos assumidos, compras de prédios".
} 
de D. Viçoso, mas de seus coadjutores, o Colégio Nossa Senhora das Dores, em São João del-Rei, em 1898.

Esses são apenas três exemplos que ajudam a pensar as estratégias de afirmação de projetos católicos em solo mineiro. Nestes casos, os três são de iniciativa das vicentinas, voltados para a formação feminina, cuja intencionalidade consistia em fortalecer o ideário de romanização do catolicismo em solo mineiro.

Com vistas a fortalecer a instituição clerical, a Cúria Romana desenvolveu algumas atividades, entre elas o envio de novas congregações para o Brasil, com preferência as que haviam completado a formação em Roma ou em seminários europeus. A vinda das congregações masculinas e femininas foi incentivada para colaborarem com o episcopado nas atividades pastorais, no campo educacional e em assistências sociais. Os reformadores pretendiam um clero piedoso e santo, afastado da política, da cultura brasileira e do progresso científico em geral.

De conduta rígida e puritana, esses religiosos buscavam o conhecimento profundo da doutrina. Uma educação calcada na formação moral, imprimindo-lhes o cunho cristão divino, em uma vida orientada para a busca da verdade e da perfeição. Uma formação que afastaria esses sacerdotes dos problemas socioculturais do povo brasileiro.

\section{Instalação e desdobramentos}

Em seis de janeiro de 1897,

com a bênção solemne do prédio pelo Revm Padre João de Castro, e assistencia de muitas Exm $^{\text {as }}$ famílias e cavalheiros da nossa melhor sociedade que abrilhantaram a festa com as suas presenças, incumbindose do discurso official o Dr. Balbino Cândido da Cunha, foi inaugurado, na cidade de São João del-Rei, Estado de Minas Gerais, o Colégio Nossa Senhora das Dôres ${ }^{3}$.

Sua idealização esteve diretamente relacionada à Santa Casa de Misericórdia, entidade filantrópica, cujo funcionamento se iniciou quando a cidade ainda era denominada Vila de São João, em $1783^{4}$. A idéia de construção do Colégio foi formulada pelos membros diretores da Santa Casa, mais especificamente pelo comendador José da Costa Rodrigues, provedor, e pela irmã Suzana Matricon, superiora ${ }^{5}$.

\footnotetext{
${ }^{3}$ Livro destinado ao histórico do Colégio Nossa Senhora das Dores, assinado pela Irmã Jardim. Arquivo do CNSD.

${ }^{4}$ Mais detalhes em Arruda (2011).

${ }^{5}$ A irmã Suzana Matricon capitaneou as Filhas da Caridade da Sociedade São Vicente de Paulo em sua missão na cidade de São João del-Rei. Participou ativamente da organização e funcionamento da Santa Casa de Misericórdia, fundou o Externato e o Asilo das Expostas, instituições anexas à Santa Casa.
} 
As obras do prédio que abrigou o terreno que pertencia a esta entidade tiveram início em 1895. Coube à irmã Matricon liderar o movimento de angariar donativos para auxiliar nas despesas com a construção do CNSD e do Asilo.

Atribui-se, desta forma, a participação significativa das Irmãs Vicentinas no projeto de construção, funcionamento e organização dessas instituições em que previa, entre outros propósitos, a educação feminina, com o objetivo de formar mães católicas que educariam, por sua vez, filhos católicos.

No relatório da Santa Casa, referente aos anos de 1897-1898, consta o motivo da fundação do Colégio Nossa Senhora das Dores,

tendo a administração, sérias aprehensões sobre o futuro que aguardava o nosso pio estabelecimento pelo augmento constante das despezas, já tão elevadas nestes últimos annos sem receita relativa, deliberamos fundar um collegio para meninas, sob à direção das beneméritas Irmãs de São Vicente de Paulo, visando não só [a] nova fonte de renda que garantisse os muitos serviços prestados ás classes desfavorecidas da fortuna, como também [a] concorrer para a educação das futuras mães de família. Para levar avante a idéia, incumbimos ao Dr. João Batista Maia de Lacerda de levantar a planta do edifício com capacidade para [atender a] cem alunnas, o que foi feito a contento da Mesa, que a approvou e mandou executal-a. (Relatório da Santa Casa de Misericórdia de São João del-Rei, ano compromissal de 1897-1898)

A obra teve início em 15 de outubro de 1895 e foi concluída em dezembro de 1897. O prédio, conforme consta do Relatório da Santa Casa,

mede 34 metros de frente por $19^{\mathrm{m}}, 50$ de fundo, 15 metros de altura excluída a platibanda, sendo: $1^{\mathrm{m}}, 80$ de sapata, além das fundações, $6^{\mathrm{m}}, 80$ de pé direito no primeiro pavimento e $6^{\mathrm{m}}, 40$ no segundo, ou $1.326^{\mathrm{m}^{2}}$ exceptuando cozinha, despensa, commodos para empregados, latrinas e casas de banhos com $131^{\mathrm{m}^{2}}$, ou o total de $1.457^{\mathrm{m}^{2}}$. Todas as dependências são cimentadas ou assoalhadas e forradas. Importou a sua construção com dependencias e acessórios, como gradil, portão de ferro, alpendre, grade da escada, canalisação d'água, esgotos, lavatórios, latrinas com caixas automáticas, fogão econômico com três caixas de 500 litros, mesa de marmore e bacias esmaltadas para cozinha, em Rs.135:694\$278 ou $93 \$ 132$ por metro quadrado; porém addcionando-lhe a quantia de Rs.5:362\$780, attinge a cifra de Rs.141:057\$058. (Relatório da Santa Casa de Misericórdia de São João del-Rei, ano compromissal de 18971898)

O detalhamento da construção sugere uma arquitetura marcada por um estilo atento à arte e, ao mesmo tempo, à funcionalidade, ponderando tanto o discurso da modernização arquitetônica ${ }^{6}$, quanto do papel da educação que as autoridades de ensino

\footnotetext{
${ }^{6}$ Considera-se modernização arquitetônica o estilo eclético utilizado para explicar o movimento que revolucionou a noção de estilo na arquitetura na segunda metade do século 19.
} 
propagandeavam. Chamava atenção pela elegância e imponência, tornando-se no que poderia nomear o cartão postal da cidade.

Sintonizada com o discurso em torno da necessidade da construção de prédios específicos para a escola ${ }^{7}$, assim como o aperfeiçoamento das escolas normais, a reestruturação da escola como equipamento urbano, a estruturação de novos métodos (intuitivo) e conteúdos de ensino, a iniciativa das Filhas da Caridade indica uma resposta à demanda por vagas e por instrução presentes nos discursos dos reformadores.

É reforçada nestes discursos, sobretudo no último quartel do século 19, a idéia de que a escola suplantaria outras instituições sociais de formação e socialização como a família, a igreja ou outros grupos de convívio, tornando-a, nestes termos, imprescindível a uma ação eficaz com as crianças e jovens.

Em um mesmo local deveriam agrupar-se os alunos segundo critérios etários e de nível de conhecimento, padronizando o tempo, o trabalho dos professores, a avaliação. Constitui-se, neste sentido, uma organização pedagógica que sugere a superioridade e especificidade da educação escolar suplantando outras estruturas sociais ${ }^{8}$. Esses espaços deveriam atender a instrução primária, secundária, superior e profissional, em consonância com os modernos preceitos pedagógicos e higiênicos capazes de atender a população. A aquisição de conhecimentos científicos relacionados ao ofício docente sugere a necessidade de investimento nesse nível de formação para o qual seria imputada a responsabilidade de desenvolver a metodologia moderna.

Nesta nova forma escolar ${ }^{9}$ estavam incluídas as discussões pedagógicas, sobretudo aquelas referentes às propostas metodológicas, como condição mesma de realização de sua função social específica. Assim, os defensores do método intuitivo, metodologia

\footnotetext{
${ }^{7}$ A implantação do grupo escolar na escola primária de Minas Gerais ocorreu a partir da reforma João Pinheiro. No seu governo, foi definido, por meio da lei n. 439, de 28 de setembro de 1906, no art. $3^{\circ}$ que o ensino primário seria gratuito e obrigatório e especificava que seria ministrado em: I. Escolas isoladas; II. Grupos escolares e III. Escolas-modelo, anexas às escolas normais. Fonte: APM. Lei n. 439, de 28 de setembro de 1906.

${ }^{8}$ Estudos recentes vêm demonstrando que noutros espaços, além dos escolares, figuravam uma multiplicidade de possibilidades para os que pretendiam se apoderar das habilidades de ler, escrever e contar. As casas de educação para crianças órfãs fundadas por religiosos ou leigos e as estratégias familiares de contratação de professores particulares figuram entre esses espaços onde se transmitiam valores, comportamentos, conhecimentos. Como exemplo dessa produção, ver Morais (2009). No mesmo sentido e pensando numa visão ampliada de educação, encontramos a produção e circulação de romances, jornais, revistas, sermões, apresentações teatrais, festas, pinturas e outros.

9 O termo forma escolar é aqui entendido como um conjunto de características que configuram uma unidade. Nesse conjunto, se inserem a importância das regras na aprendizagem, a organização racional do tempo (o tempo da escola), a multiplicação e a repetição de exercícios (o modo de fazer), cuja função é aprender, conforme as regras, a definição de um espaço distinto daquele de outras práticas sociais e saberes específicos a serem ensinados. A relação pedagógica (entre alunos e mestres) envolve a submissão a uma nova forma do poder. Para mais detalhes, ver Guy Vicent, Bernard Lahire e Daniel Thin (2001, p. 7-46). Segundo esses autores, a forma escolar constitui-se historicamente e, como fruto das relações sociais, está cotidianamente em mudanças ou em processos de transformação.
} 
aplicada no CNSD, argumentavam sobre a importância de o espaço da sala de aula permitir que as diversas classes pudessem realizar as lições de coisas, projeto que se mostrou sintonizado com a proposta educacional das Filhas da Caridade.

As evidências sugerem que o projeto de construção não esteve imune à renovação ou invenção de um novo modelo escolar. Foi pensado de forma a acolher esse novo ensino, bem como se adequar aos preceitos higiênicos defendidos pela medicina à época. Amplos corredores, altura do pé direito, dimensões grandiosas das janelas, portas e portões, a racionalização e higienização dos espaços formam um conjunto de preceitos que valorizavam uma simbologia estética e cultural da qual o Colégio era depositário.

Envolvido no debate, as prescrições médicas projetavam um modelo pedagógico cuja representação se fez presente no CNSD. Os cuidados higiênicos voltados para a prevenção e erradicação de doenças como a febre amarela e o cólera encontravam nos discursos dos higienistas prescrições que variavam desde a escolha do lugar aos detalhes da arquitetura, cujo descontrole poderia favorecer o surgimento e proliferação de doenças.

Aspectos como dimensões das construções, principal definidor do número de alunos, as pinturas, as paredes, o pavimento, o teto, as escadas, as janelas, o controle da umidade do ar, as salas de estudo, salas de aula, rouparia, dormitórios, refeitório, enfermaria e latrinas são alguns dos múltiplos e variados elementos presentes nesses discursos. Na perspectiva médica, esses espaços deveriam ser localizados, construídos, organizados e mantidos de modo a atender as regras prescritas pela higiene e pela pedagogia.

A possibilidade de causar males às crianças, em razão de as instalações escolares não terem sido estabelecidas com as condições adequadas, acentuava o discurso em favor de espaços e materiais higienicamente concebidos, com exposição conveniente ao sol e aos ventos. Dessa forma, havia que se preocupar com a iluminação, arejamento, alimentação, exercícios corporais, cuidados com as excreções dos organismos e com a educação dos sentidos, de modo a conservar e desenvolver as faculdades físicas, intelectuais e afetivas dos alunos. 
A ciência da higiene ${ }^{10}$, forjada gradativamente no âmbito dos cursos superiores de medicina e das sociedades científicas, desdobrava-se em múltiplos dispositivos na constituição de práticas educativas em que rotinas escolares são prescritas, o tempo das atividades de aula é organizado e o espaço escolar da educação é instituído de acordo com o que postulava o discurso da medicina.

Atento a esses requisitos e em busca de uma condição que atendesse à boa saúde nos moldes higienistas, o Colégio Nossa Senhora das Dores, conforme relata a irmã Jardim, "reun[ia] a solidez da construção às condições necessárias à boa higiene, indispensável em estabelecimentos dessa ordem" (Arquivo do Colégio Nossa Senhora das Dores, livro contendo histórico da instituição).

O extenso discurso sobre a ciência da higiene esteve presente em vários segmentos da sociedade como no dos administradores, legisladores, reformistas, sucedendo-se na Assembléia falas que insistiam na importância de se observarem as prescrições médicas, recobrindo preocupações com relação à medicina e à escola, impondo a esta os princípios, métodos e procedimentos oriundos daquela.

Por meio do discurso de Antonio Teixeira de Souza Magalhães, em relatório apresentado ao desembargador Francisco de Faria Lemos, em 1887, também é possível perceber essa representação:

A escola funccionando em prédios alugados, quase sempre mal situados sem a observância de nenhuma regra hygienica, nem pedagógica não só dificultam enormemente a acção do mestre, como tornar-se mesmo nociva á saúde dos meninos. Cumpre esforçar-se por tornar a escola um lugar possível, onde o alumno penetre com satisfação, e sem nenhum sacrifício da sua vida physica; abrir salas espaçosas, e com mobília adequada de modo a não embaraçar antes facilitar o livre desenvolvimento orgânico; estimular por meio dos objectos convenientemente escolhidos a curiosidade infantil, fallar sempre, e ao mesmo tempo, á intelligencia e aos sentidos dos meninos, em uma palavra, cumpre obedecer em nossas escolas aos preceitos da hygiene e aos preceitos pedagógicos - si quizermos preparar, para nos substituir, uma geração que á cultura do espírito, ao desenvolvimento das idéias, juncto à perfeição e o vigor do corpo $^{11}$.

Os problemas educacionais, no entanto, não estiveram restritos às questões higiênicas, pois outros elementos estiveram na ordem do dia, tais como as condições de

${ }^{10}$ O termo é utilizado por Gondra no livro Arte de civilizar (2004) para se referir ao movimento higienista deflagrado no século 19 na constituição do campo médico em cujo "ato discursivo constituiu a higiene como uma evidência científica que naturaliza a intervenção" (Prefácio Marta carvalho, p. 14). Ao buscar a legitimidade no campo, o discurso da medicina foi constituído como uma ciência "desautorizando e desqualificando outros discursos e outras práticas, de modo a se projetar nos diferentes estratos da sociedade como autoridades portadoras de um conhecimento suficiente e necessário para regular tanto a vida do indivíduo como a ordem social" (Gondra, 2004, p. 31).

${ }^{11}$ Relatório da Diretoria Geral da Instrução Pública da Província de Minas Gerais anexo ao relatório do sr. Antonio Teixeira de Souza Magalhães, p. 8-9. Ouro Preto, em: 25 out. 1887. 
trabalho, de estrutura e a situação financeira, conforme registrado em mensagem dirigida ao congresso mineiro, em 1898, pelo então presidente do Estado de Minas Gerais, dr. Crispim Bias Fortes:

Torna-se preciso [...] que doteis o Poder Executivo de recursos para construção de casas onde funcionam as escolas de instrucção primária, e para aquisição do material preciso para melhor diffusão do ensino, de acordo com os modernos preceitos pedagógicos. Em muitas localidades não existem edifícios para as necessidades da instrucção e em muitas outras os destinados para esse fim são de todo imprescindíveis, quer se tenha em vista a hygiene e a pedagogia, quer as commodidades do professor. Em geral mal remunerado, tem ainda o professor primário, em muitas localidades do estado, o encargo de pagar o aluguel de casa onde funcione a escola que rege, e a casa nessas condições adquirida é quase sempre má. Mesmo os edifícios pertencentes ao Estado existentes em diversas localidades e destinadas às escolas públicas, não satisfazem as condições exigidas pela pedagogia moderna, e muitos delles precisam de concertos radicais para sua conservação ${ }^{12}$.

No mesmo discurso, o presidente Chrispim Jacques Bias Fortes sugeria uma melhor distribuição das escolas públicas existentes, em vez de criar outras, bem como remunerar melhor os professores, incluindo os das Escolas Normais.

Em outra direção, o desembargador Francisco de Faria Lemos sugere que "talvez seja preferível, em vez de prover as cadeiras, animar e desenvolver o ensino particular, dando-lhe subvenção maior do que a fixada no regulamento $n$. 100, não tornando este auxílio dependente das condições que o mesmo regulamento prescreve" ${ }^{13}$. Argumenta o desembargador que a quantia necessária ao provimento dessas cadeiras (481) subvencionaria o duplo ou o triplo de escolas particulares.

Para o inspetor geral da Instrução Pública, dr. Mathias de Vilhena Valladão, em relatório apresentado em outubro de 1886, o insucesso do ensino é atribuído "à péssima organização das escolas normais". Para que o ensino fosse bem-sucedido, faltavam dois elementos essenciais na perspectiva do inspetor: "a educação científica e a educação moral: uma que lhe dá força do espírito, o amor ao estudo; outra que lhe apura os sentimentos, e dá-lhes a consciência, a compreensão nítida da importância e da grandeza de sua missão"14.

A necessidade de reforma das escolas normais mantidas e reforçadas nos discursos posteriores sugere que a forma incipiente, assistemática e descontínua, aliada aos

\footnotetext{
${ }^{12}$ Mensagem dirigida pelo presidente do Estado de Minas Gerais, dr. Chispim Jacques Bias Fortes, ao congresso mineiro em 1898.

${ }^{13}$ Fala do desembargador Francisco Faria Lemos, dirigido à Assembléia Provincial de Minas Gerais em 4 de maio de 1886.

14 Relatório da Inspetoria Geral da Instrução Pública da Província de Minas Gerais, Ouro Preto, 25 de outubro de 1886, anexo ao relatório do presidente da Província em 1887.
} 
insuficientes recursos impossibilitava a construção de um projeto de educação capaz de atender à população.

Em meio a esse cenário, na perspectiva de oferecer uma formação docente calcada em princípios de moralidade, civilidade e de pertencimento à pátria é que foi autorizada, pelas autoridades de ensino e pela sociedade são-joanense, a fundação do Colégio Normal Nossa Senhora das Dores, em São João del-Rei, sob os auspícios das Filhas da Caridade da Sociedade São Vicente de Paulo, em cujo projeto esses agentes depositavam confiança.

Nesse sentido, de braços dados com o Estado, o projeto das Filhas da Caridade buscava ocupar lugar central no seio da sociedade, a fim de dar visibilidade aos seus princípios e métodos e, desse modo, obter reconhecimento social. A formação de novos quadros para o magistério, o cuidado da infância e a disseminação do espírito nacional presentes nos discursos de reformistas procurava ir ao encontro do ideal de uma escola Normal que abarcasse tanto os saberes pela experiência quanto a aplicação de seus métodos.

Dessa forma, o preparo docente e a educação para o trabalho se tornaram uma emergência, uma necessidade, projetando uma educação que deveria permear a formação de professores firmada nos princípios modernos. No caso mineiro, e mais particularmente de São João del-Rei, projetavam a continuidade com base em uma visão cristã e católica da realidade social.

A disponibilidade para trabalhar com as inovações didático-pedagógicas (globos, cartazes, coleções, carteiras, cadernos, livros), surgidas no final do século 19, aliada a uma proposta de ensino que se propunha inovadora, método intuitivo, no desenvolvimento dos saberes científicos, no atendimento aos preceitos da medicina e, no interior desse, da higiene, e sua aproximação ao fazer pedagógico, e a nova organização espaço-temporal da dinâmica escolar constituíram as condições de possibilidade para a criação e funcionamento do CNSD na cidade de São João del-Rei, sem contrariar a tradição católica que procurava articular ciência e fé.

\section{A cidade: palco de atuação das religiosas}

Nas últimas décadas do século 19, São João del-Rei foi palco de transformações urbanas decorrentes da prosperidade e do comércio que, "além de possuir uma boa capacidade de acumulação de capitais na intermediação dos negócios interprovinciais" (Graça Filho, 2002, p. 25). 
Essa riqueza, somada à que provinha das fábricas e do comércio, fez com que a cidade progredisse e trouxesse consigo o aumento da sua população ${ }^{15}$, decorrente da vinda de imigrantes à procura de oportunidades no espaço urbano, assim como dos escravos libertos. A modernidade, nestes termos, foi reafirmada como uma urgência para o período com entrelaçamentos entre ambientes urbanos e escolares, emergindo daí a necessidade de disciplinar a população.

A idéia é reforçada no âmbito do Estado Republicano e a escola pensada como aquela que seria capaz de governar corpos e população em resposta às urgências sociais, econômicas e políticas.

A instalação do Colégio em São João del-Rei constituiu um fato de destaque dados os processos de modernização e urbanização. São João del-Rei, em sua especificidade, passou, no início do século 20, por mudanças importantes, marcados pelo discurso da modernidade e do progresso. A modernidade aqui considerada como as transformações no espaço urbano encontrou, na cidade, um espaço privilegiado para a sua materialização. Nela, uma nova paisagem se projetou tendo como base 0 desenvolvimento industrial, a remodelação dos espaços, os novos meios de comunicação e o crescimento populacional.

As práticas de reconfiguração urbana, advindas de concepções políticas, econômicas, culturais, sociais e educacionais, possibilitam a compreensão de que, na tentativa de configurar o cenário moderno, estratégias foram acionadas de modo a provocar interferências no modo de ser, pensar e agir capaz de conformar, na população, uma atitude moderna (Foucault, 2000). Os hábitos populares se tornavam alvo de especial atenção e medidas foram tomadas para adequar homens e mulheres, inculcando-lhes valores e formas de comportamentos que passavam pela rígida disciplinarização do espaço e do tempo.

\footnotetext{
${ }^{15}$ São João del-Rei, ao longo do século 19, duplica o número de habitantes. Segundo Alexandre Mendes Cunha (2007), a população de São João del-Rei em 1838, entre livres e cativos, somava cerca de 7.000 habitantes. Em 1859, já seria, aproximadamente, de 8.500. Segundo Graça Filho (2007), em 1872, a população da cidade era de 10.733 habitantes. Se a este número acrescentarmos os municípios, no mesmo período, chegaria a 35.000. No entanto, o jornal Arauto de Minas, de 14 de abril de 1877, em folhetim, informava que a população urbana de São João del-Rei era de 8.110 habitantes, dos quais 1.359 eram escravos, 3.908 pardos e 1.739 pretos, registrando uma queda na população em comparação aos números apresentados por Graça Filho. Segundo os dados do recenseamento de 31 de dezembro de 1900, a população de São João del-Rei era de 54.132 habitantes, sendo 27.185 homens e 26.947 mulheres. (Synopse do recenseamento, Rio de Janeiro, Typograia da Estatística, 1905). Sobre a modernidade em São João del-Rei ver Ribeiro, Rúbia Soraya Lelis. As fotografias de André Belo (18791941): imagens da modernidade em São João del-Rei. Belo Horizonte: UFMG, 2006. 145f. Dissertação (Mestrado em Educação). Programa de Pós-Graduação em História, Universidade Federal de Minas Gerais.
} 
Nesta perspectiva, a constituição de espaços e tempos escolares recaía não só para a criação de salas de aula, mas também para a formação de professores, de modo que a modernidade fosse também incorporada aos atos, falas e modos dos habitantes.

Uma das apostas recaía sobre o investimento na expansão das áreas de atuação da forma escolar, nos moldes a que Vicent, Lahire e Thin (2001) a nomearam para se referir a uma forma especificamente escolar de socialização da infância e da juventude. Nesse novo formato, buscavam-se a configuração e a difusão da instituição escolar, cujos saberes e práticas específicos de sociabilidades, uma vez despertados, inculcados e exercitados nos espaços e tempos escolares, deveriam ultrapassar os muros e portões da escola (Faria Filho, 1998) e viessem contribuir para a reconstrução e organização do espaço público da cidade.

Nessa medida, tomada pelas necessidades e exigências sociais que insistiam na urgência em controlar e fiscalizar a ocupação populacional no ideal de reorganizar o cenário urbano, estiveram em cena preocupações em resignificar os possíveis papéis que seriam desempenhados pela população ${ }^{16}$.

A esta instituição escolar moderna coube o papel de inventar tradições (Hobsbawm, 1997), em que valores e normas de comportamentos seriam inculcados por meio de um conjunto de práticas, cujos princípios e conteúdos serviriam à coesão social e à legitimação hierárquica.

Os primeiros anos de funcionamento do CNSD já projetavam progressos expressivos com vistas a atender às novas demandas. Com dois pavimentos, dez anos depois já anunciava reformas,

attendendo ao número progressivo de alumnas, a Mesa teve necessidade de fazer algumas obras indispensáveis no Collegio, que constaram da divisão de três aulas para música e desenho, competentemente mobiliadas, por serem insufficientes as que existiam ${ }^{17}$.

Tancredo Braga, ao organizar um álbum sobre São João del-Rei, em 1913, afirmava que a instrução era bem ministrada na cidade e, ao se referir ao CNSD, menciona o atendimento a 400 alunas e três cursos: primário, normal e artes, com aulas de pintura, flores, trabalhos de agulha, bordados, música, canto e outros. Essas atividades, no entanto, estiveram incluídas no plano extracurricular.

\footnotetext{
${ }^{16}$ Estudo acerca dessas preocupações foram desenvolvidas por Silva (2009). O cenário, no entanto, reporta a cidade do Rio de Janeiro e Buenos Aires nos anos 1920. Maiores detalhes em SILVA, José Claudio Sooma. Teatros da modernidade: representações de cidade e de escola primária no Rio de Janeiro e em Buenos Aires nos anos 1920. Rio de Janeiro: Uerj, 2009. 308f. Tese (Doutorado em Educação). Programa de Pós-Graduação em Educação, Universidade do Estado do Rio de Janeiro.

${ }^{17}$ RSCM, ano compromissal 1907/1908.
} 
As características do Colégio, ao reunir as prescrições higiênicas em consonância com os aspectos propositivos dos médicos, o portão de ferro destacado por escadarias, sugerindo preocupação em demonstrar segurança em que as alunas pudessem ser ensinadas sob vigilância constante das Filhas da Caridade, a estátua da Virgem SS. da Medalha Milagrosa no frontispício do prédio principal, são alguns elementos que ajudam a pensar as estratégias de ação das religiosas para viabilizar o funcionamento do projeto vicentino e, ao mesmo tempo, dilatar, expandir, multiplicar a doutrina que encarnavam por meio da eleição do público bem determinado. No caso, ocupando-se da formação feminina, a pedagogia, a instituição e os sujeitos comprometidos com esse projeto objetivavam atingir a casa, a escola e a formação de quadros para a própria ordem.

Nessa espécie de ação ramificada, os dirigentes da congregação procuraram estabelecer e legitimar dispositivos de autorregulação e reprodução de uma matriz de formação de larga tradição na história da educação.

\section{A educação feminina}

A expansão da educação feminina, assim como o fortalecimento da religião e das interdições ao mundo moderno, tiveram suas discussões fortalecidas no século 19. Em um quadro social em que os agentes eram avaliados pela religiosidade, pelos valores morais e, no caso das mulheres, pelas prendas domésticas, uma profissão que reunisse esses padrões indiciava as condições de possibilidades das mulheres ao ofício e a uma certa independência, sugerindo um grande passo para a realização pessoal. Nestes termos,

uma profissão que não demandasse [...] romper barreiras sociais, causando conflitos familiares por sua possibilidade de comprometer o casamento e a maternidade. Bastava que o trabalho fosse honesto, aprovado e considerado acessível. Um trabalho digno, que permitisse cuidar do lar e ainda proporcionar um certo conforto com o salário recebido e que, principalmente, fosse bem aceito e devidamente autorizado pelo meio familiar e social. (Almeida, 1998, p. 168)

Como se pode observar, uma representação que associa a condição de mãe, esposa e professora construída no meio social e que foi paulatinamente incorporada pela mulher, não sem resistência. Uma profissão que não demandasse romper com as barreiras sociais, que não colocasse em risco o casamento e a maternidade, somada ao status de um trabalho honesto, aprovado e considerado acessível, que permitisse cuidar do lar, reunia as condições favoráveis ao acesso da mulher ao ofício.

Tanto o Estado, quanto a Igreja, buscam, por meio desse público, reforçar sua inserção social nas relações político-religiosas locais. Minas Gerais, conforme analisa 
Muniz (2003), fora identificada como de gente modesta e ordeira, condição que viria se somar a outras como as anteriormente citadas.

Por outro lado, a questão em debate dizia respeito à qualificação docente rumo a uma maior profissionalização. Haveria de se formar profissionais em consonância com o novo método. O processo artesanal vinha sendo debatido e a proposta tinha como pressuposto a adoção de métodos científicamente fundamentados, indicando as escolas normais como local privilegiado de formação de professores, assim como o estabelecimento de um repertório de saberes que unificasse a prática do professorado. Neste novo quadro de remodelação, estiveram envolvidos, ainda, o cuidado da infância e a disseminação do espírito nacional.

O método intuitivo, uma inovação européia criada no século 19, chega ao Brasil no final do século, propondo renovação epistemológica, reafirmando a importância dos sentidos para a aprendizagem, privilegiando a observação e a experiência como atividades cognitivas. Caracterizado internacionalmente como uma invenção da escola moderna, o método viria substituir o caráter abstrato e pouco utilitário da instrução. Conforme observa Valdemarin (2000), sua utilização impulsionou a produção de inúmeros manuais, destinados a alunos e professores, exemplificando procedimentos e conteúdos de ensino capazes de concretizar as inovações pretendidas.

Estudos sobre escolas normais no Brasil sugerem o século 19 como o período de sua implantação, ficando a cargo das Províncias a responsabilidade de cuidar do ensino elementar e do preparo de seus professores. Com relação às escolas normais, o que evidencia esses estudos são características comuns, marcadas por incertezas e precariedades no seu funcionamento. Não só as inconstâncias nas datas de criação e a de instalação, de aberturas, fechamentos e reaberturas estiveram presentes no movimento de constituição da maioria dessas escolas, também as diretrizes metodológicas se alternavam de acordo com a definição de seus dirigentes, com ações, muitas vezes personificadas ${ }^{18}$

Associadas ao projeto de constituição do Estado nacional moderno, as escolas normais públicas brasileiras, vinculadas à preocupação em levar a instrução a todos, buscavam imprimir uma identidade de hábitos intelectuais e morais na população. Seja como idéia, seja como efetivação, essas escolas foram pensadas para atender alunos homens e mulheres.

\footnotetext{
${ }^{18}$ Estudos detalhados sobre a história de criação dessas escolas podem ser observados no livro organizado por Araújo et al (orgs.). As escolas normais no Brasil: do império à república. Campinas: Alínea, 2008.
} 
No final do século 19, configura-se a expressiva inserção das mulheres na docência elementar, em substituição aos professores do sexo masculino, associada à expressiva legitimação de um modelo mais econômico: a escola primária mista. Carecia, no entanto, fazer com que os pais tomassem consciência da importância da escola e fizessem com que seus filhos e filhas a freqüentassem regularmente. Desconfiados da escola pública, a elite, para quem os professores não davam garantias de saber e moralidade, davam preferência para o ensino particular em escolas confessionais.

Aliando princípios de moralidade, dos quais a Igreja não abria mão, aos de civilidade e pertencimento à pátria, nos moldes da constituição do Estado-nação, é que foi autorizada a fundação do Colégio Normal Nossa Senhora das Dores em São João delRei, sob os auspícios das Filhas da Caridade, em cujo projeto os agentes sociais da localidade depositavam confiança.

O fato é que, utilizando de estratégias, seja no formato da construção do prédio, seja na adoção do método de ensino, o Colégio se fez presente às inovações, cujo projeto as Filhas da Caridade contribuíram para dar visibilidade.

A formação de novos quadros para o magistério, o cuidado da infância e a disseminação do espírito nacional presentes nos discursos de reformistas após a república iam ao encontro do ideal de uma escola normal que abarcasse tanto os saberes pelas experiências quanto a aplicação de seus métodos. Dessa forma, o preparo docente e a educação para o trabalho se tornaram uma emergência, uma necessidade, projetando uma educação que permeasse a formação de professores firmada sobre os princípios modernos.

Não por acaso esse processo ocorreu no interior de um movimento social de racionalização do tempo, próprio das relações capitalistas que se estabeleciam naquele momento. No caso mineiro, e mais particularmente em São João del Rei, projetavam a continuidade com base em uma visão cristã e católica da realidade social.

Nesse sentido, de braços dados com o Estado, o projeto das Vicentinas buscava ocupar lugar central no seio da sociedade a fim de dar visibilidade aos seus princípios e métodos e, desse modo, obter reconhecimento social.

\section{A formação docente}

Uma incursão sobre as possibilidades de acesso à profissão docente na cidade levou-me a investigar os acontecimentos que envolveram a extinção de uma Escola Normal pública, fundada em São João del-Rei, em 1883. Seu funcionamento, no entanto, 
durou pouco mais de vinte anos, sendo extinta em 1906. As razões apontadas em discursos dos administradores e legisladores figuram entre as mais diversas ordens.

Em argumento apresentado pela Comissão Especial de reorganização dos serviços públicos do Estado de Minas Gerais, em $1901^{19}$, entre outras propostas, uma propõe suprimir as escolas normais existentes. Na mesma legislação, ficou estabelecido que os professores continuariam a receber a metade de seus vencimentos, por um ano, a contar da data da lei, salvo se os professores, por proposta da congregação, se obrigassem, dentro de sessenta dias, a continuar no exercício de suas funções, apesar da redução dos vencimentos. Essa condição possibilitava dar continuidade ao funcionamento das escolas "si as Câmaras Municipais dos lugares onde existirem Escolas Normais quiserem manter esses estabelecimentos". Para tal, deveriam entrar em acordo, dentro de um ano, com o Governo do Estado, que, neste caso, prorrogaria o prazo das disposições antecedentes.

Embora essa condição tenha sido aceita pelos professores da Escola Normal de São João del-Rei, a fragilidade instaurada com esse novo dispositivo teria vida curta. Nem a ajuda financeira proposta no orçamento municipal da cidade conseguiu sustentar essa condição, culminando com o fechamento definitivo da escola em 1906.

Esforços, no entanto, foram empreendidos pela comunidade no intuito de evitar a extinção da escola. Em 1906, foi expedido, pelos membros da Câmara Municipal de São João del-Rei, ao corpo legislativo do Estado de Minas Gerais, uma correspondência em que apresentavam os serviços prestados à educação popular deste município, exaltavam a freqüência sempre crescente dos estudantes da Escola Normal, assim como o número de professores e professoras por ela diplomados.

Reportando-se ao relatório apresentado pelo diretor da Escola, relativo ao ano de 1905, informavam que, naquele ano, estavam matriculados 103 alunos e ranqueando-a, em relação às escolas normais do país, em quinto lugar na ordem de freqüência.

Nessa mesma correspondência, os autores faziam menção a um Colégio equiparado na cidade, visto como aquele que servia apenas para os que a fortuna favorecia. Com isso, apelavam para o censo de justiça, solicitando o restabelecimento da Escola Normal, "satisfazendo a justa aspiração não só do município, mas de todo o estado de Minas Gerais"20.

Em 1906, no governo de João Pinheiro, foi instalada na capital, Belo Horizonte, uma Escola Normal Modelo, que funcionou como um laboratório de práticas que seria estendido a todo o Estado. Em 16 de dezembro de 1906, por meio do decreto n. 1906, foi

\footnotetext{
${ }^{19}$ Lei n. 318 , art. $6^{\circ}$, capítulo 3.

20 Ata da Câmara Municipal de São João del-Rei, 1905.
} 
aprovado um regulamento que serviria de base para a organização da instrução primária e normal do Estado.

Do que se pode perceber, o fechamento da escola normal também se relaciona a uma concorrência que se instaurou na cidade, pois, em 1898, conforme apresentado neste trabalho, foi fundado na cidade, o Colégio Normal Nossa Senhora das Dores, uma instituição confessional, de cunho religioso, voltado para a formação de professoras primárias.

Como já mencionado, em 1905 o Curso Normal oferecido por esse Colégio foi equiparado às escolas normais oficiais do Estado, sendo uma das razões, segundo os indícios sugerem, para a extinção da escola normal pública, já que, para alguns, não justificava o funcionamento simultâneo de duas escolas de formação primária na mesma região.

O fato é que a legitimidade conquistada pelo CNSD se viu ampliada com o novo estatuto jurídico de 1905. O término da experiência de pouco mais de duas décadas da escola normal pública foi, e ainda é, sinal de força das irmãs na cidade, eficiência de estratégia e de efetividade da ação educativa protagonizada pelas vicentinas em São João del-Rei.

\section{A escolha pela profissão}

A escolha pela profissão pareceu-me ser uma oportunidade do trabalho fora do lar: "Era uma oportunidade de aprender uma profissão, ter uma ocupação", relata Aurene Maria David, ex-aluna do Colégio. Em uma época em que havia poucos lugares permitidos a uma mulher de família, freqüentar uma escola propiciava um ponto de encontro e possibilidade de articulação das mulheres entre si. Somava-se a isso a instituição de novos hábitos e comportamentos, especialmente aqueles ligados às transformações urbanas, produzindo novas demandas sociais.

A identificação da mulher na atividade docente, como extensão da maternidade, não subverteria sua função feminina primordial que não só poderia como deveria ser ampliada. Para tanto, seria importante que o magistério também fosse representado como uma atividade de amor, de entrega e doação. Essas características, consideradas tipicamente femininas, articuladas à tradição religiosa da cidade, reforçavam a idéia de que a docência deveria ser percebida mais como um sacerdócio e um gesto de entrega do que propriamente como uma profissão.

Assim é que a presença significativa da religião e da moral cristã no currículo perpassava todo o ensino ministrado no Colégio, sacralizando o ofício, cuja imagem se 
fundamentava em modelos de comportamentos e na produção de representações sobre o professor ideal. Assim como assinalam Villela (2002) e Gondra e Schueler (2008), dentre outros, percebemos que essas representações se encontravam diretamente ligadas a atributos exemplares, tais como a calma, modéstia, reserva, disciplina, discrição e capacidade para administrar, disciplinar e vigiar.

Esses atributos deveriam estar presentes tanto no domínio da atividade docente quanto nas atividades do cotidiano da vida doméstica. As jovens normalistas, muitas delas também atraídas pela necessidade de trabalho, seriam cercadas por restrições e cuidados para que a profissionalização não se chocasse com sua feminilidade.

O Colégio Nossa Senhora das Dores formava a jovem para ser dona de casa, depois para o magistério, nessa ordem, como fez questão de afirmar a ex-aluna Aurene. Para isso, era necessário que estivessem preparadas e soubessem portar-se adequadamente em sociedade. Além disso, a possibilidade de ascenderem às instâncias formais da educação, sobretudo para as mulheres de uma cidade do interior como São João del Rei, deveu-se, naquele momento, quase que exclusivamente ao CNSD, posto que havia apenas duas escolas secundárias na cidade nos moldes aqui apresentados, uma para cada sexo: para o masculino, o Ginásio Santo Antônio e, para o feminino, o Colégio Nossa Senhora das Dores.

Ainda que a instrução no Colégio tenha sido simbolizada na sagrada missão, tanto da maternidade, quanto da manutenção da natureza feminina, do recato e do pudor, da ação educadora dos filhos e filhas, as novidades das ciências e os ideais positivistas se fizeram presentes no seu cotidiano, em especial as ciências que tratavam das ocupações femininas.

O aproveitamento do tempo à noite, em família, o hábito de economizar, simbolizado na expressão o tempo é ouro, foram incorporados à disciplina de Economia Doméstica nos primeiros anos de funcionamento da instituição, consistindo na aprendizagem de saberes dirigidos à administração da vida familiar. As principais atribuições para o governo da casa, assim como o vestuário e sua conservação, foram temas incorporados aos conteúdos programáticos.

A associação entre pecado e sexo sem fins de procriação, assumida pelo cristianismo, é uma das razões para a valorização da virtude. Assim é que se exigia das alunas o respeito aos costumes, regras, normas e convenções. Sob o olhar vigilante das religiosas, buscava-se formar jovens cultas, polidas, sociáveis, mas, sobretudo, cristãs, católicas convictas, que difundissem na família e na sociedade os valores da religião. 


\section{Considerações finais}

Em São João del-Rei a possibilidade da profissionalização do magistério primário para as mulheres começou a ser pensada a partir da instalação da primeira escola normal na cidade, uma instituição pública voltada para ambos os sexos. A intensidade com que esse projeto buscou se firmar na sociedade, no entanto, indica que se tratava de algo em construção, não instituído, assim como demonstra o quadro de criação da maioria das escolas normais no Brasil $^{21}$, que eram marcadas por fragilidades, ingerências administrativas e, principalmente, pela ausência de investimentos financeiros para sua difusão e consolidação.

O final do século 19 é caracterizado como um momento em que as mulheres ocuparam o espaço da sala de aula e se constituíram na maioria do corpo docente das escolas primárias. Representante da época no que se referia ao potencial progressista da educação e da moral, os discursos concebiam o feminino como sinônimo de cuidado e ternura, condição possibilitada pela fixação da mulher como professora da escolarização inicial. A mulher, nesses termos, poderia e deveria se responsabilizar pela instrução e educação de meninas e meninos.

O estudo aponta que tanto a questão financeira, quanto o projeto de reordenação católica, se apresentam no rol das possibilidades de inserção das mulheres no magistério. Pode-se dizer que o CNSD, por meio das Filhas da Caridade da Sociedade São Vicente de Paulo, deixou marcas em São João del-Rei como uma escola católica, o que reforça a larga tradição de fazer da escola um instrumento de afirmação da fé.

Para tal, muito contribuiu o estatuto jurídico adquirido em 1905, ampliando a legitimidade conquistada pelo CNSD, constituindo sinal de força, na eficiência de estratégias e de efetividade da ação educativa protagonizada pelas vicentinas em São João del-Rei.

\section{Referências}

ALGRANTI, Leila Mezan. Honradas e devotas: mulheres da Colônia - condição feminina nos conventos e recolhimentos do sudeste do Brasil (1750-1822). Rio de Janeiro: José Olympio, 1999.

ALMEIDA, Jane Soares de. Mulher e educação: a paixão pelo possível. São Paulo: Unesp, 1998.

ARRUDA, Maria Aparecida. Formar almas, plasmar corações, dirigir vontades: o projeto educacional das Filhas da Caridade da Sociedade São Vicente de Paulo (1898-1905). Rio de Janeiro: Uerj, 2011. 252f. Tese (Doutorado em Educação). Programa de PósGraduação, Universidade do Estado do Rio de Janeiro.

${ }^{21}$ Sobre a criação, organização e funcionamento das escolas normais no Brasil ver Araújo et al. (2011). 
ARAÚJO, José Carlos Souza et al (orgs.). As escolas normais no Brasil: do império à república. Campinas: Alínea, 2008.

ARAUJO, Maria Marta. Do governo econômico e policial da cidade ou das normas e disciplina que mantêm a civilização. In: VENÂNCIO, Renato Pinto; ARAÚJO, Maia Marta (orgs.). São João del-Rei: uma cidade no Império. Belo Horizonte: Secretaria de Estado de Cultura de Minas Gerais. Arquivo Público Mineiro, 2007, p. 83-99.

CARVALHO, Marta Maria Chagas de. A articulação entre a concepção teórica e o universo empírico da pesquisa: um depoimento. Série Documental, MEC/Inep. Seminário História da Educação Brasileira: a ótica dos pesquisadores. Belo Horizonte, 1995.

CUNHA, Alexandre Mendes. A evolução urbana de São João del-Rei. In: VENÂNCIO, Renato Pinto; ARAÚJO, Maria Marta (orgs.). São João Del-Rei: uma cidade no Império. Belo Horizonte: Secretaria de Estado de Cultura de Minas Gerais, Arquivo Público Mineiro, 2007, p. 19-30.

FARIA FILHO, Luciano Mendes de. O espaço escolar como objeto da História da Educação: algumas reflexões. Revista da Faculdade de Educação. São Paulo, v. 24, n. 1, jan./jun., 1998, p. 141-159.

FOUCAULT, Michel. O que são as luzes. In: MOTTA, Manoel (org.). Foucault: ditos e escritos 2. Rio de Janeiro: Forense, 2000.

GONDRA, José Gonçalves; SCHUELER, Alessandra. Educação, poder e sociedade no império brasileiro. São Paulo: Cortez, 2008.

GONDRA, José Gonçalves. Artes de civilizar: medicina, higiene e educação escolar na corte imperial. Rio de Janeiro: DP\&A, 2005.

GRAÇA FILHO, Afonso de Alencastro. A princesa do oeste e o mito da decadência de Minas Gerais - São João del-Rei (1831-1888). São Paulo: Annablume, 2002.

HOBSBAWM, Eric; RANGER, Terence (orgs.). A invenção das tradições. Rio de Janeiro: Paz e Terra, 1997.

LEONARDI, Paula. Igreja católica e educação feminina: uma outra perspectiva. Revista HISTEDBR On-line, Campinas, n. 34, jun, 2009, p. 180-198.

MORAIS, Christianni Cardoso. Posses e usos da cultura escrita e difusão da escola de Portugal ao Ultramar, Vila e Termo de São João del-Rei, Minas Gerais (1750-1850). Belo Horizonte: UFMG, 2009. 376f. Tese (Doutorado em História). Programa de PósGraduação em História, Universidade Federal de Minas Gerais.

MUNIZ, Diva do Couto. Um toque de gênero: história e educação em Minas Gerais (18351892), Brasília: UNB/Finatec, 2003.

RIBEIRO, Rúbia Soraya Lelis. As fotografias de André Belo (1879-1941): imagens da modernidade em São João del-Rei. Belo Horizonte: UFMS, 2006. 145f. Dissertação (Mestrado em Educação). Programa de Pós-Graduação em História, Universidade Federal de Minas Gerais.

SILVA, José Claudio Sooma. Teatros da modernidade: representações de cidade e de escola primária no Rio de Janeiro e em Buenos Aires nos anos 1920. Rio de Janeiro: Uerj, 2009, 308f. Tese (Doutorado em Educação). Programa de Pós-Graduação em Educação, Universidade do Estado do Rio de Janeiro.

VALDEMARIM, Vera Teresa. Lições de coisas: concepção científica e projeto modernizador para a sociedade. Cadernos Cedes, Campinas: Unicamp, v. 19, n. 52, 2000 , p. $74-87$. 
VINCENT, Guy; LAHIRE, Bernard; THIN, Daniel. Sobre a história e a teoria da forma escolar. Educação em Revista, Belo Horizonte, n. 33, 2001, p. 7-47.

VILLELA, Heloisa. Da palmatória à lanterna mágica: a escola normal da província do Rio de Janeiro entre o artesanato e a formação profissional (1868-1876). São Paulo: USP, 2002. 291f. Tese (Doutorado em Educação). Programa de Pós-Graduação em Educação, Universidade de São Paulo.

MARIA APARECIDA ARRUDA é professora adjunta na Universidade Federal de São João del-Rei.

Endereço: Rua Manoel Esteves dos Santos, 75/301 - 36307-224 - São João delRei, MG - Brasil.

E-mail: arrudacida@yahoo.com.br.

Recebido em 10 de março de 2012.

Aceito em 3 de julho de 2012. 